\title{
A IMIGRAÇÃO HAITIANA EM SANTA CATARINA: FASES E CONTRADIÇÕES DA INSERÇÃO LABORAL
}

\author{
Luís Felipe Aires Magalhães \\ (Doutorando no Programa de Pós-Graduação em Demografia da Universidade Estadual \\ de Campinas - Unicamp; Pesquisador no Observatório das Migrações de Santa Catarina \\ - UDESC) \\ E-mail: lufeaires@gmail.com \\ Prof. Dra. Rosana Baeninger \\ (Departamento de Demografia da Universidade Estadual de Campinas - Unicamp; \\ Coordenadora do Observatório das Migrações de São Paulo - FAPESP/CNPq- \\ NEPO/UNICAMP; orientadora e co-autora). \\ E-mail: baeninger@nepo.unicamp.br
}

O Haiti é um país caracterizado por intensa tradição emigrante. Desde o final do século XIX, países como República Dominicana, Cuba, Canadá, França e Estados Unidos, constituíram-se como destinos históricos. Com a crise capitalista de 2008, o acirramento de seletividades migratórias nestes destinos e a própria expansão econômica brasileira e sua presença no Haiti, essa emigração passou a se direcionar, após 2010, ao Brasil. Atualmente, estima-se haver mais de 50.000 haitianos residentes no Brasil, com destaque para quatro municípios catarinenses: Chapecó, Itajaí, Joinville e Blumenau. Este artigo objetiva apresentar as fases da inserção laboral desta força de trabalho e suas principais contradições. Parte-se da hipótese de que já podem ser identificadas mudanças neste perfil, bem como uma mobilidade interna desta migração internacional, que nos permitem definir etapas da presença haitiana no Estado. A metodologia contempla utilização de revisão teórica (para a reflexão sobre as origens do fluxo e sua chegada a Santa Catarina), pesquisa em fontes de dados administrativos (do Ministério do Trabalho e Emprego e da Polícia Federal, para a formulação do perfil migrante) e trabalho de campo de natureza qualitativa em Balneário Camboriú e Chapecó (para a verificação das hipóteses levantadas).

Palavras-Chave: Imigração haitiana; Santa Catarina; Trabalho.

\section{A IMIGRAÇÃO HAITIANA EM SANTA CATARINA: FASES E CONTRADIÇÕES DA INSERÇÃO LABORAL \\ BREVE HISTÓRIA DO HAITI - OS PROCESSOS HISTÓRICOS DE EMIGRAÇÃO NO PAÍS}

O Haiti expressa, como poucos países do mundo, o sucesso do projeto colonial na América Latina: de colônia mais próspera do século XVII e XVIII, se transformou em país mais pobre da América atualmente (PIERRE-CHARLES, 1990, JAMES, 2010). A revolta escrava no país, pelo controle nacional e também pelos preceitos de liberdade, igualdade e fraternidade, ocasionou um dos episódios mais fecundos da história contemporânea: a Independência Negra do Haiti, a $1^{\circ}$ de Janeiro de 1804 (JAMES, 2010). Conquistada duramente, a Independência Haitiana deparou-se, rapidamente, com os entraves colocados pelas potências imperialista de sua época, que condenaram e 


\section{SEMINÁRIO DE PESQUISA EM CIÊNCIAS HUMANAS - SEPECH \\ Humanidades, Estado e desafios didático-científicos \\ Londrina, 27 a 29 de julho de 2016}

condenam ainda o país à uma situação de completa marginalidade na divisão internacional do trabalho (JAMES, 2010).

A situação de dependência que se forma a partir de imposições externas e da subalternidade na divisão internacional do trabalho condiciona, historicamente, a formação de diversos fluxos emigratórios do país, de modo que a emigração haitiana não é um fenômeno novo. Pelo menos desde o final do século XIX, a emigração haitiana dirige-se à República Dominicana e Cuba, países que à época passavam por crescimento de sua indústria açucareira - para a qual se dirigiram esses emigrantes.

Desde os anos 1960, ela tem crescido sistematicamente, em especial para países centrais no sistema capitalista, como Estados Unidos e França. Estes fluxos migratórios possuem um conteúdo histórico que não pode ser desprezado e lança luzes sobre a própria presença haitiana no Brasil: tanto Estados Unidos como França são países que historicamente exercem controle econômico, político e inclusive militar sobre o Haiti. (CASTOR, 1971).

Atualmente, 1.134.000 haitianos residem fora do país, isto é, $11,05 \%$ da população do país (MPI, 2013). Historicamente, os Estados Unidos são o destino preferencial dos emigrantes haitianos. De 1960 até 2010, o total de emigrantes haitianos nos Estados Unidos passou de 5.000 para 606.000 , chegando, atualmente, a representar $1,5 \%$ de toda a população imigrante norte-americana (MPI, 2014).

\section{TRANSFORMAÇÕES NA ECONOMIA MUNDIAL: CRISE E SELETIVIDADES MIGRATÓRIAS}

A crise capitalista pós-2008 operou uma importante transformação na dinâmica das migrações internacionais. A diminuição do ritmo de expansão econômica, logo transformada em recessão, gerou efeitos diretos sobre as condições de trabalho e de remuneração nos países centrais. Paralelo ao crescimento do desemprego, o nível dos salários diminuiu e, particularmente nos países europeus, uma série de reformas trabalhistas e previdenciárias subtraíram direitos historicamente conquistados. No que se refere às condições sociais da população imigrante, a crise reforçou seletividades migratórias, seja no campo do discurso, com a ascensão de grupos e partidos de extrema-direita declaradamente contrários ao recebimento de imigrantes e refugiados, seja no campo da prática, com reformas na legislação migratória e ataques e discriminações sistemáticas aos estrangeiros residentes na Europa e nos Estados Unidos (MAGALHÃES e BAENINGER, 2014).

Para os imigrantes e suas famílias, a crise apresentaria ainda um efeito adicional, de fundamental importância para a reflexão sobre a reorientação dos tradicionais fluxos da emigração haitiana: a diminuição dos níveis de remessas de migrantes. Segundo dados da CEPAL, a principal via de contágio da crise nos países da América Latina foi, precisamente, a diminuição do volume de remessas de migrantes (CEPAL, 2009).

O Haiti é um país cuja economia depende das remessas de migrantes (MAGALHÃES e BAENINGER, 2014). Estima-se que o aporte destes recursos no país represente $150 \%$ do valor de suas exportações, e entre $22 \%$ e $26 \%$ de seu Produto Interno Bruto (PIB). A diminuição destes recursos indica, em nossa interpretação, ser um elemento importante da reorientação dos fluxos da emigração haitiana que lhe seguiria, especialmente sua vinda para o Brasil. Para nos aproximarmos, no entanto, desta hipótese, é importante 


\section{SEMINÁRIO DE PESQUISA EM CIÊNCIAS HUMANAS - SEPECH \\ Humanidades, Estado e desafios didático-científicos \\ Londrina, 27 a 29 de julho de 2016}

considerarmos que a seletividade migratória e a diminuição das remessas explicam mais os fluxos afastarem-se dos destinos clássicos que propriamente direcionarem-se ao Brasil. Para tal, é necessário avaliarmos ainda o reposicionamento do país no cenário das relações internacionais, particularmente no que se refere à presença econômica e militar brasileira no Haiti.

Respondendo à crise de 2008 com políticas anti-cíclicas promotoras de expansão econômica e com crescimento no nível de empregos, o Brasil, que já ocupava militar e economicamente o Haiti através da coordenação da Minustah (Missão da ONU para o reestabelecimento da paz no país) passa a ocupar o imaginário social haitiano como um país de oportunidades e de relativa facilidade no acesso, acolhimento e documentação (METZNER, 2014). Desde 2010, pelo menos 50 mil haitianos migraram ao Brasil (FERNANDES, 2014).

\section{A IMIGRAÇÃO HAITIANA AO BRASIL}

A imigração haitiana inicia-se no Brasil ainda no ano de 2010, com a concentração de, naquela época, pequenos grupos de imigrantes haitianos na fronteira do Brasil com o Peru, particularmente nos Estados do Acre e do Amazonas. Em pesquisa recente ainda não publicada, Magalhães, Silva e Assis (2015) identificaram, através da análise de 108 reportagens jornalísticas sobre a imigração haitiana no Brasil, que em Maio de 2010 já havia reportagens sobre i) crianças haitianas caminhando sozinhas no centro da cidade de São Paulo e ii) um grupo de 12 imigrantes haitianos, sendo oito adultos e 4 menores de idade, residentes no Estado do Mato Grosso do Sul.

A viagem ao Brasil dá-se de duas formas diferentes, segundo a condição de documentação dos imigrantes. Se documentada, a rota envolve uma viagem direta de Porto Príncipe, no Haiti, ou Santo Domingo, na República Dominicana, ao Aeroporto Internacional de Guarulhos, em São Paulo. Essa condição de documentação não é predominante em termos do total de imigrantes haitianos que chegaram ao Brasil, especialmente até o ano de 2015. Se, por outro lado, a condição do imigrante for de ausência da documentação, o caminho predominante inclui uma viagem até o Equador ou ao Peru. Segundo Patarra (2012),

o processo de entrada desses imigrantes em território brasileiro é semelhante na quase totalidade dos casos. A viagem começa em Porto Príncipe ou na República Dominicana, e por via aérea chegam a Lima, Peru, ou em Quito, no Equador, países que não exigiam visto de entrada para os haitianos. Destas duas cidades partem por via terrestre em uma viagem que pode se estender por mais de um mês, ao longo do percurso eles vão alternando trechos percorridos em ônibus e barcos" (PATARRA, 2012, ps. 13-14).

Os imigrantes haitianos, com isso, cruzam, em viagens longas de ônibus, o território peruano. Todavia, nem todos que chegam ao Equador dirigem-se ao Brasil: embora este seja o movimento predominante, muitos ficam no Equador ou mesmo no Peru, e outros dirigem-se à Argentina e ao Chile. Alguns destes últimos dirigem-se, por fim, igualmente ao Brasil (OIM, 2014). Quanto á documentação, 


\title{
XI SEMINÁRIO DE PESQUISA EM CIÊNCIAS HUMANAS - SEPECH \\ Humanidades, Estado e desafios didático-científicos \\ Londrina, 27 a 29 de julho de 2016
}

\begin{abstract}
A abertura desse processo leva à emissão de um protocolo que permite ao imigrante a obtenção de carteira de trabalho e CPF provisórios, enquanto a solicitação de refúgio é analisada pelo CONARE. Tais documentos são essenciais para o ingresso do imigrante no mercado formal de trabalho e o envio de remessas. Por tal solicitação de refúgio não se enquadrar nos requisitos definidos em lei e convenções internacionais, ela é recusada. Ante essa situação, que levaria à permanência irregular dos haitianos no Brasil, o governo federal tomou medidas para que tal fato não acontecesse e, em janeiro de 2012, por meio de Resolução Normativa - RN ( $\left.n^{\circ} 97\right)$ do Conselho Nacional de Imigração - CNIg, concedeu visto humanitário permanente pelo prazo de cinco anos aos imigrantes haitianos. (FERNANDES, 2014, p. 14).
\end{abstract}

Entre 2010 e 2014, foram emitidas 35.534 carteiras de trabalho para haitianos no Brasil, volume que constituiu o país como a principal nacionalidade estrangeira no mercado formal de trabalho brasileira $(26,04 \%$ de um total de 136.444 carteiras de trabalho emitidas). Há de se considerar que esse novo fenômeno da dinâmica migratória brasileira não significou necessariamente, a extinção de outros fluxos mais antigos, como o de sul americanos. Entre 2010 e 2014, foram emitidas 12.344 novas carteiras de trabalho para bolivianos, 9.544 para argentinos, 9.077 para paraguaios, 6.744 para peruanos, 6.279 para uruguaios e 4266 para colombianos.

\section{A IMIGRAÇÃO HAITIANA EM SANTA CATARINA}

Mas como chegaram, no início de 2011, os primeiros imigrantes haitianos ao Estado de Santa Catarina?

A resposta a esta questão não é uma só: desde 2011, há pelo menos duas fases da presença haitiana, apontando para formas distintas de chegada, permanência e sociabilidade.

A primeira fase da presença haitiana em Santa Catarina é marcada pelos processos de recrutamento (no Acre, Amazonas e São Paulo) como motores da concentração inicial dos imigrantes haitianos, particularmente nas cidades da Mesorregião do Vale do Itajaí. Referindo-se a 2012 e à dispersão pelo território brasileiro da população imigrante haitiana que se havia concentrado em Manaus - AM, Costa (2016) afirma que este ano "foi marcado pela presença de empregadores de outros estados, principalmente do Paraná, do Rio Grande do Sul e de Santa Catarina. O primeiro grupo de 26 haitianos partiu para Itajaí [SC], no dia 01 de Fevereiro" (COSTA, 2016, p. 40).

Pesquisa de campo realizada no município de Balneário Camboriú indica haver uma forte atuação de três empresas catarinenses no recrutamento de força de trabalho, ainda no Acre. Essas empresas foram as primeiras no Estado a irem até as cidades fronteiriças do Acre buscar imigrantes haitianos. São elas: Multilog, Ambiental e Imbrasul.

A Multilog é uma empresa de logística em comércio exterior, sediada no município de Itajaí, vizinho de Balneário Camboriú. Seu principal produto é a armazenagem de bens, seu transporte para exportação, especialmente no Mercosul, e outros serviços conexos. Os imigrantes haitianos recrutados no Acre pela Multilog desempenham, essencialmente, a função de estivadores, estoquistas e de serviços gerais. 


\section{SEMINÁRIO DE PESQUISA EM CIÊNCIAS HUMANAS - SEPECH \\ Humanidades, Estado e desafios didático-científicos \\ Londrina, 27 a 29 de julho de 2016}

A Ambiental é uma empresa de execução de obras e de realização de serviços de limpeza urbana em nove cidades do Estado de Santa Catarina: Balneário Camboriú, Camboriú, Itajaí, Itapema, Indaial, Jaraguá do Sul, Joinville, São Francisco do Sul e São José. Além da coleta e transporte de lixo, a Ambiental faz ainda tratamento de resíduos sólidos e operações de saneamento básico, e emprega diretamente mais de 1.800 trabalhadores. Os imigrantes haitianos recrutados no Acre pela Ambiental desempenham, essencialmente, as funções de garis e de serviços gerais.

A Imbrasul Construtora e Incorporadora é uma empresa sediada no município de Navegantes, distante $34 \mathrm{~km}$ de Balneário Camboriú. Constrói edifícios de alto padrão na região, especialmente na praia de Gravatá. Os imigrantes haitianos recrutados no Acre pela Imbrasul desempenham, essencialmente, as funções de pedreiro, auxiliar de pedreiro, servente e serviços gerais.

Em síntese: os primeiros haitianos em Santa Catarina trabalhavam como garis no município de Balneário Camboriú e no porto de Itajaí. Alguns haviam sido recrutados no Acre para trabalhar na construção civil em Navegantes, mas logo mudaram-se para Balneário Camboriú. Realizavam, portanto, tarefas mais intensas no uso da força física. Foi apenas posteriormente que os trabalhadores haitianos dirigiram-se ao trabalho nos outros setores, principalmente o de supermercados.

\section{A FASE DA DISPERSÃO E AS CONTRADIÇÕES LABORAIS}

Para muitos imigrantes haitianos residentes na região, as cidades do Vale do Itajaí não são a última etapa da sua trajetória migratória. Especialmente a partir de 2014, tem-se verificado uma mobilidade interna destes imigrantes pelo Estado, especialmente rumo à Mesorregião Oeste de Santa Catarina. Esta dispersão pelo Estado inaugura a segunda fase da presença haitiana em Santa Catarina e nos aproxima das principais contradições da inserção laboral destes imigrantes.

Regularmente, são realizados recrutamentos de empresas frigoríferas do Oeste de Santa Catarina nas cidades do Vale do Itajaí, especialmente Balneário Camboriú. Pudemos participar de uma das reuniões de recrutamento, no que percebemos a utilização da promessa do alojamento gratuito (na realidade, há desconto da folha salarial). Até nosso último levantamento, foram 150 imigrantes haitianos residentes em Balneário Camboriú que deixaram a cidade com destino a Chapecó. A cidade de Chapecó é a segunda cidade no Brasil que mais realizou admissões de haitianos no mercado formal de trabalho (CAGED/MTE, 2015), atrás apenas de Curitiba - PR. Das dez cidades com maior volume de admissão de trabalhadores haitianos em 2014 no Brasil, 4 delas são catarinenses (Chapecó, Itajaí, Joinville e Blumenau), como se pode ver na Tabela 2: 


\section{SEMINÁRIO DE PESQUISA EM CIÊNCIAS HUMANAS - SEPECH \\ Humanidades, Estado e desafios didático-científicos \\ Londrina, 27 a 29 de julho de 2016}

\begin{tabular}{lrrrr}
\hline Município & \multicolumn{1}{c}{ Admissão } & Demissão & \multicolumn{1}{l}{ Saldo } \\
\hline Curitiba - PR & 1432 & 710 & 722 \\
\hline Chapecó - SC & 680 & 130 & 550 \\
\hline São Paulo - SP & 629 & 294 & 335 \\
\hline Cuiabá - MT & 588 & 304 & 284 \\
\hline Itajaí - SC & 579 & 220 & 359 \\
\hline Cascavel - PR & 574 & 141 & 433 \\
\hline Joinville - SC & 558 & 220 & 338 \\
\hline Porto Alegre - RS & 466 & 175 & 291 \\
\hline Blumenau - SC & 401 & 171 & 230 \\
\hline Contagem - MG & 396 & 126 & 270 \\
\hline Outros & 11274 & 4299 & 6975 \\
\hline
\end{tabular}

Tabela 2 - Cidades brasileiras que mais admitiram trabalhadores haitianos no mercado de trabalho formal (2014)

Fonte: CAGED/MTE, 2015.

Com a dispersão pelo território catarinense, a resposta à pergunta inicial (como estes migrantes, que chegam ao Brasil pelo Acre, Amazonas ou São Paulo) chegaram à Santa Catarina passa a ter então uma segunda resposta, que não exclui a primeira, mas que marca uma especificidade da fase atual da presença haitiana no estado: a atuação das redes sociais. Os amigos e parentes que já migraram dão referências positivas do lugar àqueles que ficaram no Haiti ou estão em outro país, os incentivando a migrar a Santa Catarina e construindo, com isto, uma rede de relações sociais e laborais na qual o migrante se inserirá. Previamente, já se tem garantias de emprego, hospedagem e ajuda inicial. Todos estes elementos são facilmente observados entre os haitianos em Balneário Camboriú: a rede social, fortalecida pela criação da Associação dos Haitianos em Balneário Camboriú em Março de 2013, é o que verdadeiramente dá sequência hoje ao fluxo, especialmente através do desejo e iniciativa de trazer à Balneário Camboriú os parentes que ficaram no Haiti.

Outro aspecto desta etapa atual do fluxo de imigrantes haitianos é a proporção maior de crianças e mulheres, especialmente nos ônibus que têm chegado do Acre nos últimos meses. Este proporção maior indica utilização da possibilidade do visto de reunificação familiar, que permite a vinda dos familiares residentes no Haiti ao Brasil.

As redes sociais, materializadas hoje no espaço de ajuda mútua representado pela Associação dos Haitianos da cidade, são um elemento fundamental da atual conjuntura migratória internacional e de como Balneário Camboriú se insere nela. E pela dispersão no território, não apenas Balneário Camboriú mas várias outras cidades, conforme se pode ver no Mapa 1. 


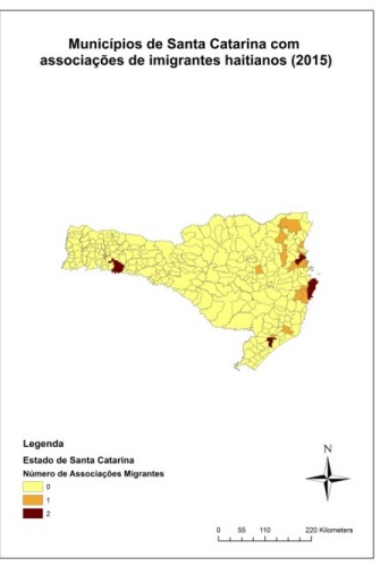

Mapa 1 - Municípios catarinenses segundo presença de associações e grupos de apoio a imigrantes haitianos (2015).

Fonte: Levantamento realizado pelos autores, 2015.

Estas associações são, sobretudo, de natureza cultural, e expressam a capacidade mobilizadora e associativa destes imigrantes, mesmo em condições adversas.

Analisando a imigração haitiana em Santa Catarina a partir de dados administrativos do mercado formal de trabalho, Cavalcanti, Oliveira e Tonhati (2014) indicam concordância com a ideia de expansão do fluxo de haitianos em Santa Catarina.

O impacto da presença dos haitianos salta aos olhos. Os haitianos contavam 0 (zero) indivíduos empregados em Santa Catarina no ano de 2011, passando para 75 em 2012 e saltando para $1.281 \mathrm{em} \mathrm{2013.} \mathrm{Em}$ apenas dois anos, deixaram de ser desconhecidos para virar o grupo mais numeroso. Os haitianos representam, no estado de Santa Catarina, $29,3 \%$ dos estrangeiros com vínculo formal de trabalho em 2013 (CAVALCANTI, OLIVEIRA e TONHATI, 2014, p. 71).

Realizamos atividade de pesquisa de campo no município de Chapecó, acompanhados de membros da diretoria da Associação dos Haitianos de Chapecó; buscamos visitar os alojamentos de trabalhadores de frigoríficos da cidade e investigar, participando, atividades culturais no âmbito das associações. A ida a Chapecó foi motivada por conta de participação em atividades de recrutamento em Balneário Camboriú, nas quais promessas (de salário, de condições de trabalho e de alojamento) foram feitas para incentivar centenas de imigrantes haitianos a deixar Balneário Camboriú e se mudarem para Chapecó, para o trabalho nos frigoríficos. A nossa reunião com a Associação e a visita a um alojamento de trabalhadores de frigorífico nos apresentou um conjunto de contradições da inserção laboral que necessita ser melhor compreendido.

Internamente, percebe-se que, em 2014, Chapecó foi o município que mais admitiu trabalhadores haitianos, mas apenas o $6^{\circ} \mathrm{em}$ termos de demissão, o que indica uma absorção desta força de trabalho maior que nas demais cidades. 


\section{SEMINÁRIO DE PESQUISA EM CIÊNCIAS HUMANAS - SEPECH \\ Humanidades, Estado e desafios didático-científicos \\ Londrina, 27 a 29 de julho de 2016}

\begin{tabular}{|c|c|c|c|}
\hline Município & Admitidos & Demitidos & Saldo \\
\hline Chapecó & 842 & 195 & 647 \\
\hline Florianópolis & 791 & 446 & 345 \\
\hline Joinville & 653 & 273 & 380 \\
\hline Itajaí & 631 & 248 & 383 \\
\hline Balneário Camboriú & 563 & 259 & 304 \\
\hline Blumenau & 473 & 204 & 269 \\
\hline Criciúma & 378 & 149 & 229 \\
\hline Xaxim & 306 & 85 & 221 \\
\hline São José & 248 & 83 & 165 \\
\hline Palhoça & 221 & 91 & 130 \\
\hline
\end{tabular}

Quadro 1 - Admissão, Demissão e Saldo de trabalhadores de nacionalidade haitiana em Santa Catarina (2014):

Fonte: CAGED/TEM, 2015.

Isto não significa, certamente, que as relações de trabalho sejam melhores em Chapecó.

Para Gerardo Iglesias da UITA - União Internacional de Trabalhadores na Indústria de Alimentos e Agricultura - a absorção de mão-de-obra de novos rostos de imigrante que chegam ao Brasil tem sido absorvida pelos frigoríficos devido a elevada desistência de trabalhadores e trabalhadoras nacionais, que consideram essa atividade 'massacrante' e 'penosa'. (ZAMBERLAM et al, 2014, p. 15).

A concentração de trabalhadores estrangeiros em geral, e haitianos em particular, em setores mais precários do mercado de trabalho formal no Brasil atesta, em realidade, não apenas as estratégias clássicas de utilização do trabalho imigrante para um emprego subremunerado, mas ainda pelo menos três formas de emprego de haitianos para superexploração desta força de trabalho.

A primeira estratégia reside na forma com que os alojamentos são "oferecidos" como diferencial no trabalho do frigorífico. A mesma equipe que apresentou à Associação dos Haitianos de Balneário Camboriú o questionário da pesquisa que seria aplicado na cidade presenciou uma reunião de recrutamento em que o alojamento foi oferecido como a principal vantagem diante dos alugueis caros de Balneário Camboriú. O alojamento seria, por consequência, descontado da folha salarial. Diante da mobilidade gerada entre Balneário Camboriú e Chapecó, fomos até a cidade do Oeste Catarinense averiguar as condições do alojamento. $\mathrm{O}$ que encontramos (e que já suscitou denúncias formais de outros órgãos e entidades ao Centro de Referência em Direitos Humanos (CRDH) da Universidade Federal da Fronteira Sul, presente no município) foram condições precárias de alojamento: em um galpão improvisado viviam 44 trabalhadores haitianos de um frigorífico, em 4 módulos. Cada módulo reunia dois quatros e um banheiro para 11 pessoas. O pé-direito era consideravelmente baixo: para os trabalhadores mais altos, apenas um palmo acima de suas cabeças. Inúmeras eram as infiltrações, inclusive sanitárias, e as rachaduras. Também era constante a falta de água no alojamento cedido pela empresa. Cedido a um preço caro: além do desconto em folha de $\mathrm{R} \$ 32,00$, o alojamento havia sido evocado para justificar, durante $\mathrm{o}$ recrutamento, uma contratação a um salário inferior ao pago aos trabalhadores brasileiros da mesma empresa.

A segunda estratégia definimos como "alocação discriminadora" no processo de trabalho. Sob esta estratégia, os trabalhadores haitianos (como também os senegaleses) são alocados de forma preferencial nas etapas de produção mais penosas e perigosas. 


\section{SEMINÁRIO DE PESQUISA EM CIÊNCIAS HUMANAS - SEPECH \\ Humanidades, Estado e desafios didático-científicos \\ Londrina, 27 a 29 de julho de 2016}

Estes etapas da produção são, por consequência, aquelas que apresentam maior incidência de acidentes de trabalho e de DORTs (Distúrbio Osteomusculares relacionados ao Trabalho). Segundo Ikedo e Ruiz (2014),

A indústria de alimentos e em particular as atividades de abate de bovinos, suínos, aves e o processamento de alimentos com carne tem posição de destaque na economia regional. As informações previdenciárias associadas à concessão de benefícios de auxílio-doença acidentários (que reconheçam o trabalho como causa de afastamento) mostram uma grande concentração dos acidentes e das doenças ocupacionais nestas atividades econômicas quando comparados com outros setores da indústria de alimentos ou com todo o setor de transformação. As doenças mentais, as doenças neurológicas e as doenças osteomusculares foram as mais importantes causas de concessão de benefícios entre estes trabalhadores, confirmando a magnitude dos riscos ergonômicos, biomecânicos e psicossociais que ameaçam a saúde dos trabalhadores nos frigoríficos (IKEDO e RUIZ, 2014, p. 39).

Nesta segunda estratégia, a extração de mais-valor se ampara na utilização de um trabalhador sub-remunerado em relação aos seus colegas brasileiros de trabalho (por conta de acordos em recrutamento realizados sem a divulgação de informações como valor médio dos salários e mesmo valor do salário após os descontos da legislação trabalhista vigente) em setores que demandam mais esforços, mais intensidade de trabalho. Que desgastam mais, portanto, a força de trabalho.

A terceira estratégia chama a atenção para uma clara e deliberada violação de direitos trabalhistas: a presença de cláusulas, em contratos de admissão e de demissão, em que o trabalhador abre mão de direitos trabalhistas sem saber, em razão de estarem estes contratos redigidos em língua portuguesa e serem eles entregues aqueles imigrantes com pouco ou nenhum domínio do idioma. Juntos, estes três mecanismos combinam-se para a extração de mais-valor, sendo utilizados ora um, ora outro, e ora os três simultaneamente. Embora esta estratégia seja implantada no chão de fábrica nos frigoríficos, seus efeitos não se restringem à unidade de trabalho, mas sim replicam-se socialmente sob a forma de discriminação, segregação e vulnerabilidade.

\section{CONCLUSÕES}

Não é forçoso considerar que este fenômeno possui condicionantes globais: a crise econômica e a seletividade migratória em países como França e Estados Unidos tiveram implicação decisiva, em um contexto de dependência de remessas, na redefinição dos fluxos e sua orientação ao Brasil. Inserir o fenômeno da migração haitiana nestes termos é importante para situar sua complexidade e evidenciar o perigo de explicações simplistas a este fenômeno, como aquelas que o creditam exclusivamente ao terremoto no país em Janeiro de 2010.

Com base nos dados administrativos, é possível concluir ainda a posição de destaque que Santa Catarina ocupa nacionalmente em termos de inserção de imigrantes haitianos no mercado formal de trabalho. Santa Catarina figurou em 2014 como o Estado com o maior número de imigrantes haitianos no mercado formal de trabalho, o terceiro Estado 


\section{SEMINÁRIO DE PESQUISA EM CIÊNCIAS HUMANAS - SEPECH \\ Humanidades, Estado e desafios didático-científicos \\ Londrina, 27 a 29 de julho de 2016}

que mais emitiu carteiras de trabalho para imigrantes haitianos, aquele que mais admitiu trabalhadores no mercado formal de trabalho, e ainda o Estado com quatro cidades na lista dos dez municípios que mais admitiram trabalhadores haitianos em 2014.

Por fim, é importante destacar que alguns elementos importantes da presença haitiana em Santa Catarina merecem uma análise específica no âmbito de uma agenda futura de pesquisa.

O processo de associabilidade dos imigrantes haitianos é um destes temas. É importante definir de forma mais precisa e específica o processo de formação das associações, suas estratégias de atuação e seus alcances políticos programáticos.

Outro tema para uma pesquisa futura refere-se à relação entre os imigrantes haitianos e outros novos imigrantes no Estado, como os ganeses, senegaleses e os refugiados sírios. Estes "encontros" étnicos têm acontecido em cidades como Chapecó (haitianos e senegaleses), Criciúma (haitianos e ganeses) e Florianópolis (haitianos e sírios). Investigar as repercussões sociais e laborais advindas de especificidades étnicas é um tema teoricamente rico; que aponta, de um lado, para as novas características que podem assumir estas cidades com a ampliação dos fluxos, e de outro, para a relação dos brasileiros com esta crescente diversidade étnica, cultural e religiosa.

\section{REFERÊNCIAS BIBLIOGRÁFICAS}

Cadastro Geral de Empregados e Desempregados (CAGED). Ministério do Trabalho e Emprego (MTE), 2015.

CASTOR, Suzy. Migración y Relaciones Internacionales (el caso haitianodominicano). México, D.F: Editora de la UNAM, 1978.

CAVALCANTI, Leonardo; OLIVEIRA, Antônio Tadeu; TONHATI, Tânia (Orgs.). A Inserção dos Imigrantes no Mercado de Trabalho Brasileiro. Cadernos do Observatório das Migrações Internacionais, Brasília, 2014.

CEPAL (2009a) La Actual Crisis Financiera Internacional Y Sus Efectos En América Latina $\quad Y \quad$ El Caribe. Disponível em: http://www.cepal.org/publicaciones/xml/0/35390/2009-25-

Thecurrentinternationalfinancialcrisis_ESPANOL-WEB.PDF. Acesso em Fevereiro de 2015.

FERNANDES, Duval; MILESI, Rosita; FARIAS, Andressa. Do Haiti para o Brasil: o novo fluxo migratório. In: Cadernos de Debates Refúgio, Migrações e Cidadania, v. 6, no 6 (2011). Brasília: Instituto Migrações e Direitos Humanos. P. 73 - 98.

Haity y la Salida Migratória, Jorge Durand. Periódico LaJornada. Disponível em http://www.jornada.unam.mx/2010/01/31/opinion/010a1pol. Acesso em Fevereiro de 2014.

IKEDO, Fernanda; RUIZ, Roberto Carlos. Trabalhar e Adoecer na Agroindústria: Da reabilitação profissional à construção da Norma Regulamentadora dos Frigoríficos (NR 36). Florianópolis - SC: Editora Insular, 2014. 


\section{SEMINÁRIO DE PESQUISA EM CIÊNCIAS HUMANAS - SEPECH \\ Humanidades, Estado e desafios didático-científicos \\ Londrina, 27 a 29 de julho de 2016}

JAMES, Ceryl. Os Jacobinos Negros: Toussaint L'Ouverture e a revolução de São Domingos. São Paulo: Boitempo Editorial, 2010. 400p.

MARINI, Ruy Mauro. Dialética da Dependência. Petrópolis: Vozes, 2000. 295p. MPI. Migration Policy Institute.

PATARRA, Neide Lopes. O Brasil: País de imigração? In: Revista E-Metropolis, $\mathrm{n}^{\circ}$ 09, ano 3, junho de 2012. Pg. $01-18$.

PIERRE-CHARLES, Gérard. Haiti (1930-1975): A Crise Ininterrupta. In: CASANOVA, Pablo González (Org.). América Latina: História de meio século, v. 3. Brasília: Editora UnB, 1990. 296p. 